\title{
THE EFFECT OF ACUPUNCTURE THERAPY ON ACTIVITY OF DAILY LIVING AND FUNCTIONAL RECOVERY IN STROKE PATIENTS: META-ANALYSIS
}

\author{
Faricha Indra Hapsari'), Setyo Sri Rahardjo²), Hanung Prasetya3) \\ ${ }^{1)}$ Masters Program in Public Health, Universitas Sebelas Maret \\ 2) Faculty of Medicine, Universitas Sebelas Maret \\ 3)Department of Acupuncture, Health Polytechnic, Ministry of Health Surakarta
}

\begin{abstract}
Background: Acupuncture is frequently advocated as an adjunct treatment during stroke rehabilitation. World Health Organization also claimed acupuncture as an effective therapy for pain, musculoskeletal disorders, and several neurologic diseases, specifically for treating stroke patients. This study conducted a systematic review and meta-analysis to critically evaluate the effect of acupuncture therapy on the activity of daily living and functional recovery in stroke patients.

Subjects and Method: A systematic review and meta-analysis was conducted by collecting articles from MEDLINE/PubMed, Science Direct, Hindawi, BMC, Plos, and Springer Link databases. The articles were filtered using PICO model, including: (1) Population $=$ patients with stroke, (2) Intervention $=$ acupuncture, (3) Comparison $=$ Sham acupuncture/control, and (4) Outcome= activities of daily living and functional recovery. Keywords used "scalp acupuncture", "acupuncture stroke", "acupuncture for functional recovery", "acupuncture for cerebral infraction", "stroke clinical trial", "acupuncture randomized controlled trial", AND "acupuncture for rehabilitation stroke". Articles included for this study were full text and randomized controlled trial that collected using PRISMA flow diagram. Quantitative data were analyzed by Review Manager (RevMan) 5.3. Results: 9 studies from Germany, California, Hungary, Korea, and China were reviewed for meta-analysis. This study showed that acupuncture elevated functional recovery in patients with stroke 0.88 units than sham/no acupuncture (Standardized Mean Different= $0.88 ; 95 \% \mathrm{CI}=-1.68$ to $-0.08 ; \mathrm{p}<0.05$ ). Acupuncture elevated activities of daily living in patients with stroke 0.96 units, but it was statistically non significant (Standardized Mean Different $=0.96 ; 95 \% \mathrm{CI}=-0.09$ to $2.01 ; \mathrm{p}>0.05$ ).

Conclusion: Acupuncture increases functional recovery, but it is needed intercollaboration with other therapy to elevate activities of daily living in patients with stroke.
\end{abstract}

Keywords: acupuncture, activities of daily living, functional recovery, stroke

\section{Correspondence:}

Faricha Indra Hapsari. Masters Program in Public Health, Universitas Sebelas Maret. Jl. Ir. Sutami 36A, Surakarta 57126, Central Java. Email: farichaindrah@gmailcom. Mobile: +6285647075776 . 